Article

\title{
Experimental Investigation on the Use of Waste Elastomeric Polymers for Bitumen Modification
}

\author{
Sadegh Yeganeh ${ }^{1}$, Mahmoud Ameri ${ }^{1, *}$, Davide Dalmazzo ${ }^{2, *}$ and Ezio Santagata ${ }^{2}(\mathbb{C}$ \\ 1 School of Civil Engineering, Iran University of Science and Technology, P.O. Box 13114-16846, Narmak, \\ Tehran, Iran \\ 2 Department of Environment, Land and Infrastructure Engineering, Politecnico di Torino, Corso Duca degli \\ Abruzzi 24, 10129 Torino, Italy \\ * Correspondence: ameri@iust.ac.ir (M.A.); davide.dalmazzo@polito.it (D.D.)
}

Received: 11 March 2020; Accepted: 7 April 2020; Published: 13 April 2020

Featured Application: The research work presented in this paper may be of value for the development and production of low-cost polymer-modified binders. Potential applications may occur in secondary roads and in developing Countries.

\begin{abstract}
The study described in this paper focused on the possible use of waste products coming from the production of styrene-butadiene rubber (SBR) and polybutadiene rubber (PBR), as bitumen modifiers. Modified binders containing these products were prepared in the laboratory with different polymer dosages and were thereafter subjected to the evaluation of empirical and rheological properties. For comparative purposes, the study also considered SBR and PBR products of premium quality. Ageing effects were also taken into account by means of proper laboratory simulations. Obtained results indicated that the two types of polymer (SBR and PBR) have completely different effects on the rheology and expected performance of the resulting modified binders. In particular, while the two polymers showed similar effects in terms of resistance to permanent deformation, the SBR products proved to be superior from the viewpoint of fatigue resistance. However, only minor differences were found when comparing the effects produced by premium quality and waste polymers. As a result of the experimental findings, it was concluded that the use of waste SBR polymers can be an attractive solution for the production of affordable modified binders.
\end{abstract}

Keywords: polymer-modified binders; styrene-butadiene rubber; polybutadiene rubber; waste products; rheological characterization; chemical characterization

\section{Introduction}

Polymers have been used extensively as bitumen modifiers to improve the performance of asphalt pavements [1-4]. Several studies have shown that such improvements occur in the form of an enhanced resistance to rutting, thermal cracking, and fatigue damage [4-8]. Further benefits, which have been reported in literature, refer to the positive changes that can be obtained in terms of temperature susceptibility, stripping resistance, and ageing behavior [9-12]. Past experience has been, for the most part, developed through the use of thermoplastic elastomers, among which the most common are styrene-butadiene-styrene (SBS), styrene-butadiene rubber (SBR) and crumb rubber (CR) derived from end-of-life tires $[4,6,13-16]$. Few studies have focused on the use of polybutadiene rubber (PBR), which is more frequently employed by the tire industry and in the manufacturing of abrasion-resistant products (including footwear, floor tiles, industrial components) [16-18].

As a result of the local availability of raw materials, SBR and PBR are among the most widely produced polymers in Iran $[17,19]$. However, it has been reported that currently employed production 
technologies lead to a relevant quantity of off-grade polymers that, in comparison to the so-called premium quality polymers, are characterized by a greater variability of their chemical and physical properties. These products possess a commercial value that is approximately equal to $30 \%$ to $50 \%$ of the value of the corresponding premium quality polymers. Thus, they are left in a shapeless form and are thereafter employed in secondary manufacturing activities. Ultimately, in the absence of adequate requests from the market, they are considered as waste products.

In view of the situation described above, an experimental investigation was carried out in order to verify the possibility of using SBR and PBR off-grade waste polymers as bitumen modifiers. Such an application would have the primary advantage of reducing production costs of polymer-modified binders (PMBs), thereby facilitating their use in infrastructures of all categories, including secondary roads in which the available budget for initial construction is usually limited. Further opportunities for use may arise in developing countries, where the introduction of paving technologies needs to be backed up by an appropriate balance between technical and financial factors.

This paper provides a synthesis of the laboratory studies that were performed on bituminous binders modified by means of different quantities of premium quality and waste SBR and PBR. Employed characterization procedures initially focused on the physical interactions taking place between bitumen and modifiers. Investigations thereafter included the assessment of performance-related rheological properties of bitumen-polymer blends in different ageing conditions.

\section{Materials and Methods}

\subsection{Preparation of $P M B s$}

Materials used in the experimental investigation for the preparation of PMBs included a 50-70 penetration grade bitumen and four elastomeric polymers. Neat bitumen (NB) was sampled at a production plant in Italy where it was employed on a regular basis for the preparation of PMBs. The four polymers were supplied by a petrochemical factory in Iran: two of them were premium quality SBR and PBR polymers, while the other two were off-grade waste products (indicated in the following as $\mathrm{w}-\mathrm{SBR}$ and $\mathrm{w}-\mathrm{PBR}$ ). All polymers were provided in bulk form and were shredded into particles smaller than $3 \mathrm{~mm}$ before being used as bitumen modifiers. Technical characteristics of the premium quality polymers declared by the producer are reported in Table 1.

Table 1. Technical characteristics of employed premium quality polymers.

\begin{tabular}{ccc}
\hline Polymer Characteristic & SBR & PBR \\
\hline Mooney viscosity (MU) & $46-58$ & $41-49$ \\
Volatile material (\%) & $<0.75$ & $<0.75$ \\
Ash content (\%) & $<1.0$ & $<0.3$ \\
Bounded styrene (\%) & $22.5-24.5$ & - \\
Cis content (\%) & - & $>96.0$ \\
Tensile strength (35 min curing) $\left(\mathrm{kg} / \mathrm{cm}^{2}\right)$ & $>250$ & $>150$ \\
Ultimate elongation (35 min curing) $(\%)$ & $>350$ & $>440$ \\
\hline
\end{tabular}

PMBs were prepared in the laboratory by making use of a high shear mixer (Silverson, model L5M-A), which was believed to be necessary in order to guarantee an adequate dispersion of the polymer in the bituminous medium $[6,10]$.

The adopted mixing procedure follows the protocol suggested by Ameri et al. [16], developed as part of a study that focused on the assessment of homogeneity and storage stability of PMBs containing the same waste polymers employed in the investigation described in this paper. After preheating bitumen at $140{ }^{\circ} \mathrm{C}$, mixing was started with a speed of $1500 \mathrm{rpm}$. As the required quantity of polymer was added to bitumen, mixing speed was gradually increased up to $4000 \mathrm{rpm}$. As a result of the high-speed rotation, temperature of the bitumen-polymer blends slowly increased during mixing. 
However, care was taken in limiting the maximum blending temperature to $160^{\circ} \mathrm{C}$. Mixing operations were completed within $40 \mathrm{~min}$ for each batch.

Polymer percentages adopted for the premium quality products (SBR and PBR) were equal to $3.0 \%$ and $4.0 \%$ (by weight of neat bitumen). When using the waste polymer products ( $w$-SBR and $w-P B R)$, an extra dosage was considered, equal to $5.0 \%$. Selection of these dosage ranges was based on a specific literature review that considered studies focusing on the use of the same types of polymers $[9,10]$. PMB samples were associated to alphanumeric codes given by the combination of polymer type ("S" for SBR, "P" for PBR), quality ("Q" for premium quality, "W" for waste), and percentage. For example, SW4 was the code given to the binder obtained by making use of $4 \%$ of the $\mathrm{w}$-SBR polymer. A complete list of the bituminous binders considered in the investigation is given in Table 2. Laboratory-prepared PMBs were characterized both in their unaged state and in the condition reached after the standard ageing procedure based on the use of the Rolling Thin Film Oven (RTFO) (ASTM D2872).

Table 2. Bituminous binders considered in the investigation.

\begin{tabular}{cccc}
\hline Binder Code & Polymer Type & Polymer Quality & Polymer Dosage (\%) \\
\hline NB & - & - & 0 \\
\hline SW3 & & Waste & 3.0 \\
SQ3 & Premium quality & 3.0 \\
SW4 & Waste & 4.0 \\
SQ4 & SBR & Premium quality & 4.0 \\
SW5 & & Waste & 5.0 \\
PW3 & & Waste & 3.0 \\
PQ3 & & Premium quality & 3.0 \\
PW4 & Waste & 4.0 \\
PQ4 & PBR & Premium quality & 4.0 \\
PW5 & & Waste & 5.0 \\
\hline
\end{tabular}

\subsection{Chemical Characterization of Components and PMBs}

Chemical characterization of component materials and of prepared PMBs was carried out with the purpose of investigating the potential interactions occurring between bitumen and polymers after mixing. Such a preliminary evaluation was deemed necessary since previous studies have proven that the final characteristics and stability of PMBs are dependent on the type of local interactions (i.e., physical or chemical) and on the relative miscibility of employed components [20-22].

Neat bitumen was subjected to thin layer chromatography (TLC) analyses, also known as SARA analyses, for the evaluation of the relative percentages of Saturates, Aromatics, Resins, and Asphaltenes [23,24]. In particular, tests were carried out by making use of the Iatroscan equipment (model MK-6), which requires the injection of small quantities $(1 \mu \mathrm{L})$ of bitumen-dichloromethane solutions $(10 \mathrm{mg} / \mathrm{mL}$ concentration) in porous quartz rods. Bitumen fractions are then identified by sequentially immerging the rod tips in a set of tanks containing n-hexane, toluene, and a mixture of dichloromethane (95\%) and methyl alcohol (5\%) [25]. The percentages of the four fractions are then assessed by means of a flame ionization detection (FID) unit, which measures the electrical current produced by combustion in hydrogen flame. SARA analyses were performed on the neat binder both in its unaged and RTFO-aged state.

Component materials and PMBs were subjected to Fourier Transform Infrared Spectroscopy (FTIR) analyses for the identification of the main organic compounds and chemical groups [26]. Investigations were carried out with the Shimadzu 8400S equipment, which relies on attenuated total reflectance (ATR) technology and allows absorbance spectra to be recorded in the wavenumber range of $4000 \mathrm{~cm}^{-1}$ to $400 \mathrm{~cm}^{-1}$ with a resolution of $4 \mathrm{~cm}^{-1}$. In all cases, tests were performed on solid samples $(1 \mathrm{~g})$ directly placed on the scanning plate. 


\subsection{Preliminary Characterization of PMBs}

Preliminary tests on PMBs included determination of penetration at $25^{\circ} \mathrm{C}$ (as per ASTM D5-05) and rotational viscosity at $135^{\circ} \mathrm{C}$ and $165^{\circ} \mathrm{C}$ (by means of a Brookfield viscometer, as per AASHTO T316-13, with the SC-21 spindle rotating at $20 \mathrm{rpm}$ ). Tests were carried out with a single repetition on unaged samples. The purpose of these tests was to collect basic information on the effects that the employed polymers may have on the hardness and resistance to flow of base bitumen. Viscosity data may also be meaningful with respect to the production of bituminous mixtures, since they are related to the energy required for pumping and control the uniformity of bitumen films covering aggregates.

\subsection{Advanced Performance-Related Characterization of PMBs}

The advanced performance-related characterization of PMBs was based on rheological tests, which were carried out by means of a Dynamic Shear Rheometer (DSR) from Anton Paar Inc. (model MCR301). Performed tests included small amplitude oscillatory shear (SAOS) tests for the assessment of linear viscoelastic properties, Multiple Stress Creep Recovery (MSCR) tests for the evaluation of resistance to permanent deformation, and Linear Amplitude Sweep (LAS) tests for the analysis of fatigue resistance. The objective of these tests was to highlight the effect of polymer modification and to identify possible differences between polymers of variable type and quality.

SAOS tests consisted in frequency sweeps covering two log decades of frequency, from $1 \mathrm{rad} / \mathrm{s}$ to $100 \mathrm{rad} / \mathrm{s}$. Test temperature was changed from $4{ }^{\circ} \mathrm{C}$ to $82{ }^{\circ} \mathrm{C}$ with $6{ }^{\circ} \mathrm{C}$ increments between each measurement step. In the range comprised between $4{ }^{\circ} \mathrm{C}$ and $34{ }^{\circ} \mathrm{C}$, tests were carried out with the 8-mm parallel plates system with a 2-mm gap, while at higher temperatures, between $34^{\circ} \mathrm{C}$ and $82{ }^{\circ} \mathrm{C}$, use was made of 25-mm parallel plates with a 1-mm gap. Measurements were performed with a single repetition in accordance with AASHTO T 315-12 both on unaged and RTFO-aged binders, verifying that imposed strain levels were kept within the linear viscoelastic domain at all temperatures and frequencies. Repeatability of the results was checked on randomly selected PMBs, verifying that the differences in results coming from different repetitions were smaller than $10 \%$. Obtained results were represented in the form of isochronal plots and Black diagrams. Furthermore, they were employed for the construction of master curves, which were fitted to the Christensen and Anderson (CA) model for frequency dependency [27] and to the Williams, Landel and Ferry (WLF) model for temperature dependency [28]. These models are indicated in the following:

$$
\left|G^{*}(\omega)\right|=G_{g}\left[1+\left(\frac{\omega_{c}}{\omega}\right)^{\frac{\log 2}{R}}\right]^{\frac{-R}{\log 2}},
$$

where $\left|G^{*}(\omega)\right|$ is the norm of the complex modulus at angular frequency $\omega, G_{g}$ is the glassy modulus, $\omega_{c}$ is the crossover frequency, and $R$ is the rheological index

$$
\log \alpha_{T}=\frac{-C_{1}\left(T-T_{R}\right)}{C_{2}+T-T_{R}}
$$

where $\alpha_{T}$ is the shift factor, $C_{1}$ and $C_{2}$ are empirically determined constants, and $T$ and $T_{R}$ are test and reference temperatures, respectively.

MSCR tests were performed with a single repetition on RTFO-aged binders in accordance with AASHTO TP70-13 in the temperature range comprised between $52{ }^{\circ} \mathrm{C}$ and $82{ }^{\circ} \mathrm{C}$ (with $6{ }^{\circ} \mathrm{C}$ increments between each measurement step). Tests entailed the application of 10 loading cycles composed of a creep phase of $1 \mathrm{~s}$ followed by a 9-s recovery. As indicated in the AASHTO standard, tests were carried out at each temperature by imposing two stress levels, equal to $0.1 \mathrm{kPa}$ and $3.2 \mathrm{kPa}$. At each stress level, results were expressed in the form of percentage recovery $\left(R_{0.1}\right.$ and $\left.R_{3.2}\right)$ and non-recoverable creep compliance $\left(\mathrm{J}_{\mathrm{nr} 0.1}\right.$ and $\left.\mathrm{J}_{\mathrm{nr} 3.2}\right)$. The percent difference in non-recoverable creep compliance $\left(\mathrm{J}_{\mathrm{nrdiff}}\right)$ was 
also considered. Obtained results were employed for the calculation of the high critical temperatures $\left(\mathrm{T}_{\mathrm{c}}\right.$ ) of investigated binders as per AASHTO M332-14 (see Section 3.3.2).

It should be mentioned that MSCR tests were proposed in order to replace the original SUPERPAVE rutting criterion based on the $G^{*} / \sin \delta$ parameter derived from SAOS tests. In particular, it was shown that such a parameter was not capable of adequately discriminating between neat and polymer-modified binders and did not show a satisfactory correlation with field performance [29-31]. Regardless of these limitations, in the study described in this paper, $G^{*} / \sin \delta$ was calculated from the results of SAOS tests for all considered binders in their unaged state (as per AASHTO M332-14), with the consequent evaluation of the corresponding high $\mathrm{T}_{\mathrm{C}}$ values.

LAS tests were carried out as per AASHTO TP101-14, at $19^{\circ} \mathrm{C}$ and $10 \mathrm{~Hz}$, by subjecting samples to a progressive growth of the applied strain amplitude, from $0.1 \%$ to $30 \%$. Each LAS test was composed by a frequency sweep test carried out in the linear viscoelastic (LVE) domain in order to characterize each material in its undamaged state, followed by an amplitude sweep test carried out in order to produce an increasing damage and evaluate failure by means of the simplified viscoelastic continuum damage (S-VECD) model [32,33]. In order to take into account the variability of test results, three replicates were run for each binder. Although the AASHTO standard refers to a failure criterion expressed in terms of maximum shear stress, in the investigation described in this paper the more recent energy-based failure criterion proposed by Wang et al. was adopted for analysis [34].

Processing of experimental data was carried out by fitting a power law model to the damage curve as indicated in the following [33]:

$$
1-C^{*}=C_{1}(S)^{C_{2}}
$$

where $C^{*}$ is pseudo-stiffness, $S$ is accumulated damage, $C_{1}$ and $C_{2}$ are fitting coefficients.

The number of cycles to failure $\left(N_{f}\right)$ corresponding to a given level of strain $(\gamma)$ was thereafter calculated by means of the following equation:

$$
N_{f}=\left[\frac{k}{a} \gamma^{\left(2+2 a \frac{c_{2}}{p}\right)}\right]^{\frac{-1}{1+\frac{c_{2}}{p}}},
$$

where $\alpha$ is a material-dependent parameter derived from the results of the frequency sweep portion of the test on undamaged samples [34], $k$ and $p$ are parameters calculated from $\alpha, C_{1}$ and $C_{2}$.

Finally, results were expressed in the form of fatigue lines (also known as Wohler curves), given by the following expression:

$$
N_{f}=A \gamma^{-B},
$$

where $A$ and $B$ are material-dependent constants.

LAS tests were performed on unaged binders. Such a choice, which is not consistent with the recommendations of the AASHTO standard, was dictated by the need to focus on the assessment of the full fatigue resistance potential of the considered PMBs, with no superposed effect due to polymer degradation and additional variability due to ageing procedures. Similar studies are documented in literature for binders containing non-conventional polymers and additives [35,36].

\section{Results and Discussion}

\subsection{Results of Chemical Characterization Tests}

Results obtained from SARA analyses performed on the neat bitumen are synthesized in Table 3, which contains the average values of the fraction percentages calculated from the five most representative rods out of the 10 rods subjected to testing. Table 3 also lists the values of the colloidal instability index $\left(\mathrm{I}_{\mathrm{c}}\right)$, calculated as the ratio between the sum of asphaltenes and saturates and the sum of resins and aromatics. Such a parameter quantifies the expected degree of instability 
of the colloidal system constituted by asphaltenes micelles peptized by resins in the saturates and aromatics medium.

Table 3. Results of SARA analyses performed on neat bitumen.

\begin{tabular}{cccccc}
\hline Ageing State & Saturates [\%] & Aromatics [\%] & Resins [\%] & Asphaltenes [\%] & $\mathbf{I}_{\mathbf{c}}$ \\
\hline Unaged & 4.2 & 62.1 & 12.6 & 21.0 & 0.34 \\
RTFO-aged & 4.0 & 57.2 & 16.2 & 22.6 & 0.36 \\
\hline
\end{tabular}

It can be observed that the considered bitumen was characterized by a high percentage of aromatics, which changed only slightly as a result of ageing. Such an outcome suggests that the binder may be adequate for modification, with the presence of a relevant quantity of macromolecules available for interaction with added polymers [20]. The very low values of the $I_{c}$ parameter also indicate that the available bitumen possessed a stable colloidal structure, with a well-balanced combination of the four component fractions.

FTIR spectra recorded for the neat bitumen, added polymers, and PMBs are provided in Figures 1 and 2. Highlighted peaks are those which correspond to styrene and butadiene blocks, located at wavelengths equal to $699 \mathrm{~cm}^{-1}$ and $966 \mathrm{~cm}^{-1}$, respectively [37]. Results for all PMBs were obtained from samples prepared with $4.0 \%$ polymer.

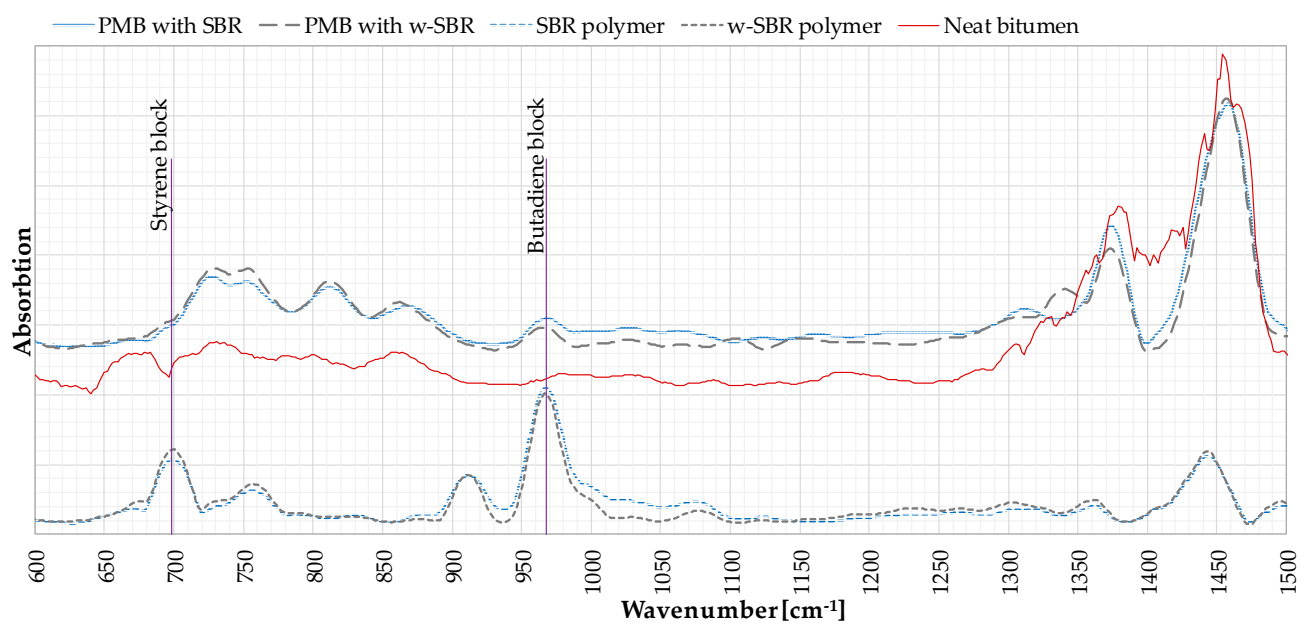

Figure 1. Results of Fourier Transform Infrared Spectroscopy (FTIR) analyses (neat bitumen, SBR and $\mathrm{w}$-SBR polymers, and SBR-modified binders).

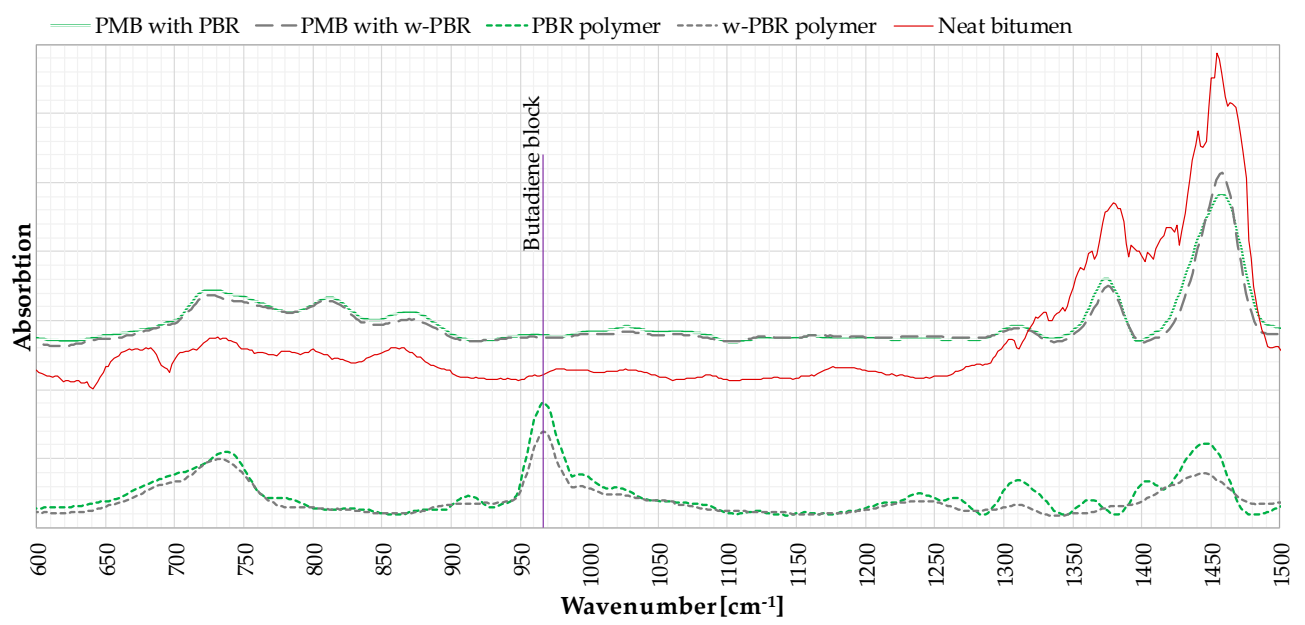

Figure 2. Results of FTIR analyses (neat bitumen, PBR and w-PBR polymers, and PBR-modified binders). 
With respect to the tests carried out on polymers, it can be observed that the two SBR products of different quality showed similar spectra, with an excellent matching of the positions of all peaks. On the contrary, greater differences were found for the PBR products, which exhibited variations in the shape of the spectra and non-negligible misalignments of some of the identified peaks.

FTIR results obtained on the PMBs indicate that the two types of polymer exhibited different interactions with employed bitumen. This can be appreciated when referring to the butadiene peaks occurring for both types of polymers (regardless of their quality) at a wavelength of $966 \mathrm{~cm}^{-1}$. In the case of the binders containing SBR or w-SBR, these peaks were clearly visible, whereas they could not be detected in the case of the binders modified with PBR and w-PBR. In particular, it was observed that these binders yielded absorbance spectra were similar to the spectrum of the neat bitumen in the entire range of wavelengths plotted in Figure 2 (between $600 \mathrm{~cm}^{-1}$ and $1500 \mathrm{~cm}^{-1}$ ).

The abovementioned findings can be interpreted by referring to the different solubility of the two types of polymer, which most probably led to the formation of different microstructures. In particular, it can be postulated that the employed SBR polymers (regardless of their quality) did not entirely dissolve in the bitumen matrix, thereby resulting in the formation of fine dispersed particles, the presence of which was associated to the previously discussed FTIR peaks. On the contrary, experimental evidence suggests that the PBR polymers were completely dissolved in bitumen, with the corresponding creation of a uniform continuous phase in which no butadiene peaks could be detected by means of FTIR analyses. These outcomes and explanations are consistent with the morphological observations performed in other research projects on PMBs containing SBR and PBR polymers by means of optical and fluorescence microscopes $[11,17,38]$. It should also be mentioned that several researchers observed that when employing high dosages of SBR, as a result of the partial miscibility of the polymer, phase separation phenomena may occur $[6,8,10,11,14]$.

\subsection{Results of Preliminary Characterization Tests}

Results obtained from penetration and viscosity tests carried out on the considered binders are listed in Table 4.

Table 4. Results of penetration and viscosity tests.

\begin{tabular}{cccc}
\hline Binder Code & $\begin{array}{c}\text { Penetration at } \\
\mathbf{2 5}{ }^{\circ} \mathbf{C}[\mathbf{d m m}]\end{array}$ & $\begin{array}{c}\text { Viscosity at } \\
\mathbf{1 3 5}{ }^{\circ} \mathbf{C}[\mathbf{P a} \cdot \mathbf{s}]\end{array}$ & $\begin{array}{c}\text { Viscosity at } \\
\mathbf{1 6 5}{ }^{\circ} \mathbf{C}[\mathbf{P a} \cdot \mathbf{s}]\end{array}$ \\
\hline NB & 62 & 0.48 & 0.13 \\
\hline SW3 & 60 & 1.11 & 0.35 \\
SQ3 & 59 & 1.16 & 0.36 \\
SW4 & 56 & 1.5 & 0.51 \\
SQ4 & 56 & 1.52 & 0.51 \\
SW5 & 54 & 2.01 & 0.72 \\
PW3 & 64 & 1.29 & 0.42 \\
PQ3 & 65 & 1.26 & 0.38 \\
PW4 & 62 & 1.88 & 0.65 \\
PQ4 & 61 & 1.65 & 0.53 \\
PW5 & 63 & 2.61 & 0.93 \\
\hline
\end{tabular}

In the case of penetration, different effects were observed for the two types of employed polymers. As expected, addition of SBR and w-SBR caused a gradual increase in consistency, with a corresponding reduction in penetration. On the contrary, PBR modification resulted in a slight increase of measured penetration. In both cases, no significant differences were found between the effects caused by polymers of different quality. These outcomes are consistent with the hypothesized differences in polymer solubility and resulting microstructure, which were discussed in Section 3.1. In particular, PBR may have completely dissolved in bitumen due to the high content of aromatics, whereas it 
may be hypothesized that SBR may have formed inner polymeric domains distributed within the bituminous matrix.

Both types of polymer caused a significant increase in viscosity, which was found to be sensitive to polymer dosage but did not depend upon polymer quality. With respect to the effect of polymer type, it was found that the use of PBR had a greater effect on the resistance to flow, with viscosity values which were greater for all dosages and test temperatures. This is also shown in Figure 3, which highlights the existence of clear relationships between polymer dosage and measured viscosity. These results seem to be consistent with the bitumen-polymer interactions investigated by means of FTIR analyses since a greater viscosity increase was expected in the case of dissolved PBR polymers in comparison to SBR polymers forming dispersed domains.

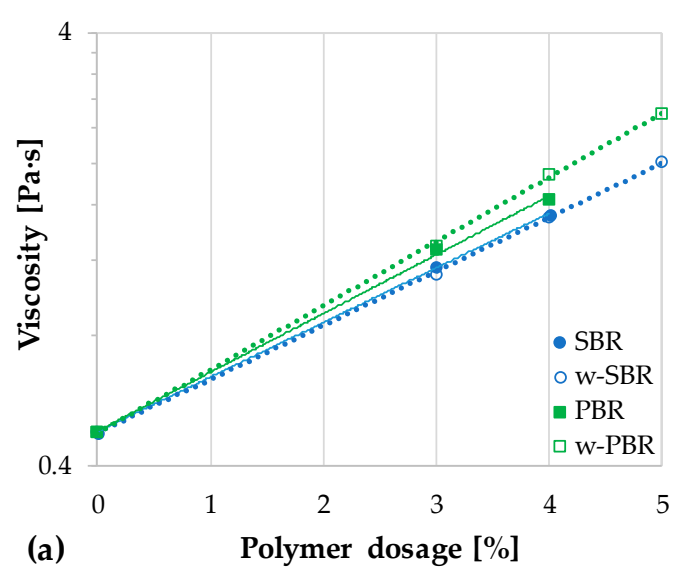

Figure 3. Results of viscosity tests: (a) at $135^{\circ} \mathrm{C}$; (b) at $165^{\circ} \mathrm{C}$.

It should be underlined that viscosity values obtained at $135^{\circ} \mathrm{C}$ were in all cases lower than the maximum limit specified in AASHTO M332-14 (equal to $3 \mathrm{~Pa} \cdot \mathrm{s}$ ), thus suggesting that the considered PMBs may be used with no concerns in ordinary operations of hot mix asphalt plants. Furthermore, at both test temperatures and for all PMBs, viscosity values recorded after initial temperature conditioning were extremely stable, thereby justifying the adoption of their average value as representative of the steady-state response.

\subsection{Results of Advanced Performance-Related Characterization Tests}

\subsubsection{SAOS Tests}

Preliminary discussion of the results obtained from SAOS tests can be made by referring to isochronal plots, in which the norm of the complex modulus and phase angle recorded at $10 \mathrm{rad} / \mathrm{s}$ are represented as a function of test temperature. This is shown in Figures 4 and 5 for SBR-modified binders and PBR-modified binders, respectively. Results obtained on binders in different ageing conditions are grouped separately.

Data plotted in Figures 4 and 5 clearly indicate that use of both types of polymers led to an enhancement of the elastic response under loading, which is proven by the remarkable reductions recorded for the phase angle at all temperatures. Such changes were directly dependent upon polymer dosage and were also slightly affected by polymer quality. In particular, when referring to the results of tests carried out on unaged samples, it was observed that by employing waste polymers, higher and lower phase angle values were obtained in the case of binders modified with SBR and PBR, respectively. In the case of RTFO-aged binders, these differences were confirmed for PMBs containing PBR, whereas, for the SBR-modified binders, no clear effects could be identified when comparing blends prepared with polymers of different quality. 


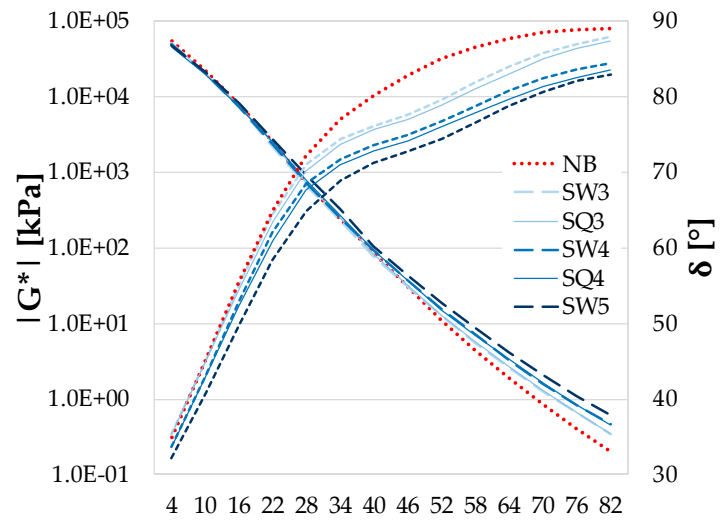

(a)

Temperature $\left[{ }^{\circ} \mathrm{C}\right]$

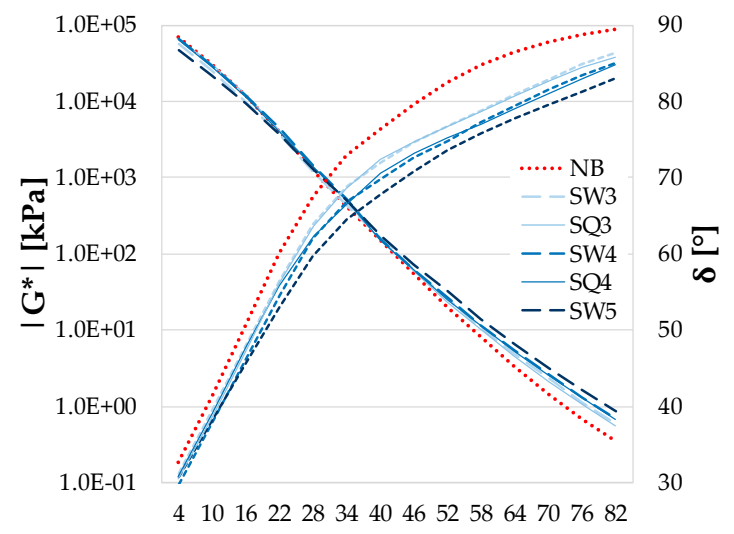

(b)

Temperature $\left[{ }^{\circ} \mathrm{C}\right]$

Figure 4. Complex modulus and phase angle isochrones (at $10 \mathrm{rad} / \mathrm{s}$ ) of SBR-modified binders: (a) unaged binders; (b) Rolling Thin Film Oven (RTFO)-aged binders.

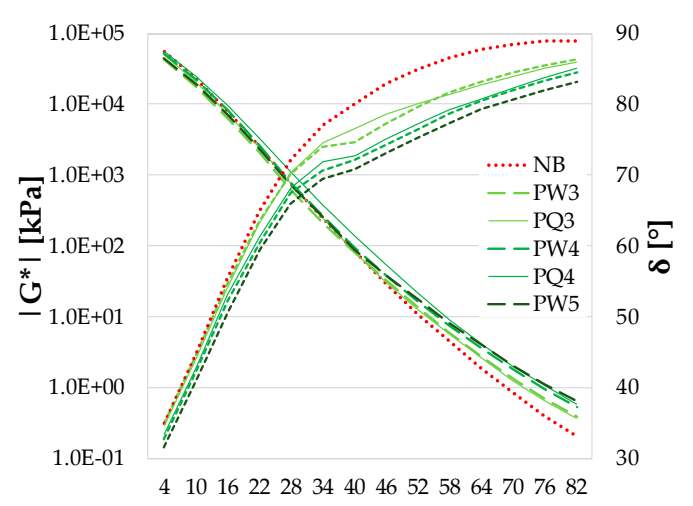

(a)

Temperature $\left[{ }^{\circ} \mathrm{C}\right]$

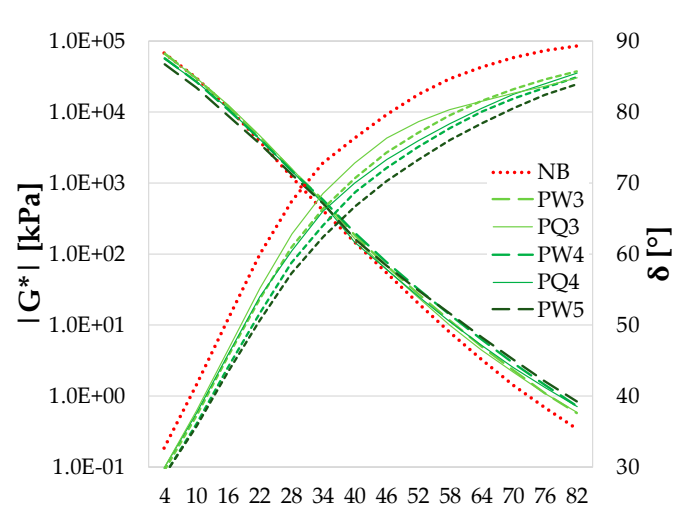

(b)

Temperature $\left[{ }^{\circ} \mathrm{C}\right]$

Figure 5. Complex modulus and phase angle isochrones (at $10 \mathrm{rad} / \mathrm{s}$ ) of PBR-modified binders: (a) unaged binders; (b) RTFO-aged binders.

As expected, all polymers had a stiffening effect on neat bitumen at high temperatures, with an increase in the complex modulus that was dependent upon polymer dosage. No specific effects were found when comparing results obtained on PMBs containing polymers of variable quality. Furthermore, the two types of polymer seemed to exhibit a very similar stiffening potential in both considered ageing states.

When focusing on low temperatures, it was observed that polymer modification led to an overall stiffness reduction. However, individual effects caused by changes in polymer type, quality, and dosage could not be easily recognized.

Figures 6 and 7 display Black diagrams that were drawn from the results of SAOS tests carried out on all binders in their unaged state by plotting measured complex modulus as a function of the corresponding phase angle. Results obtained on binders in different ageing conditions are grouped separately.

The continuity of the plots shown in Figures 6 and 7 proves that, for all binders, the time temperature equivalency principle is applicable [39]. Furthermore, the effects of polymer modification are clearly visible, with the downward shifting of all plots corresponding to the PMBs. In the case of the SBR-modified binders, such a change occurred with the creation of multiple curvatures that correspond to the presence of a more elastic phase responding to external loads in combination with the bituminous viscoelastic matrix. More monotonous plots were found for the PMBs containing PBR, which were found to be associated to a higher level of polymer dissolution in the bituminous matrix 
(see Section 3.1). The effects of variations of polymer dosage and quality were also identified as in the case of isochronal plots.
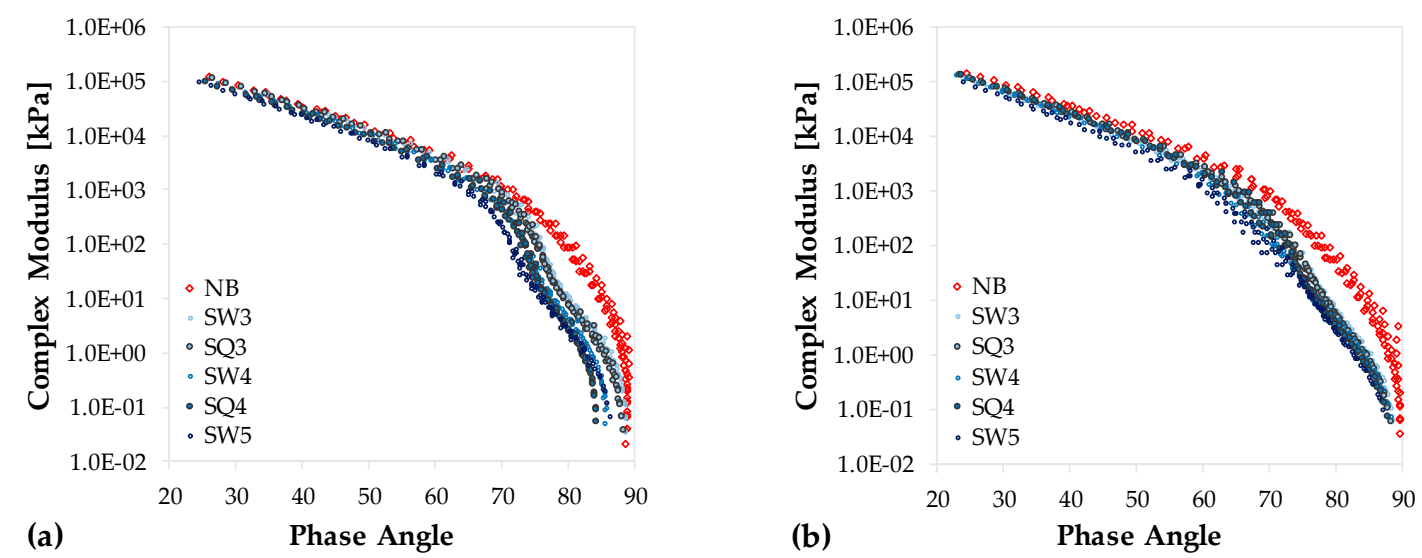

Figure 6. Black diagrams of SBR-modified binders: (a) unaged binders; (b) RTFO-aged binders.
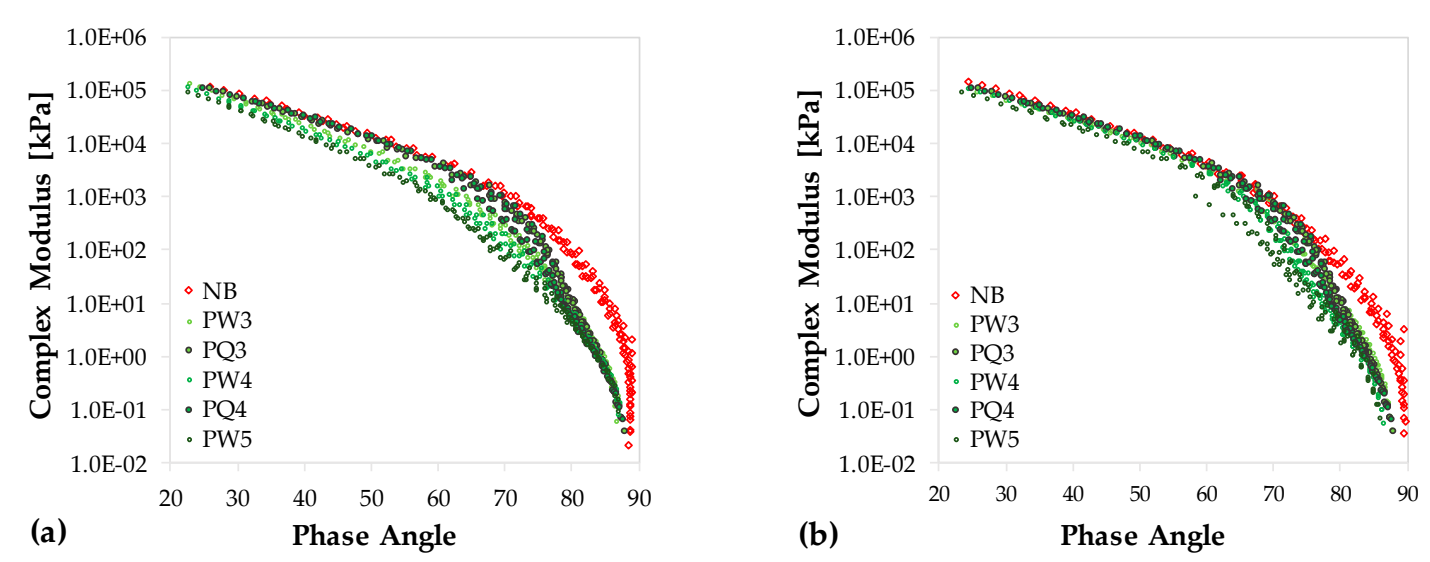

Figure 7. Black diagrams of PBR-modified binders: (a) unaged binders; (b) RTFO-aged binders.

Given the applicability of the time-temperature equivalency principle, master curves were constructed for all binders at the reference temperature of $20^{\circ} \mathrm{C}$ by means of the CA and WLF models described in Section 2.4. Corresponding results are synthesized in Table 5, which contains the values of CA model parameters $\left(G_{g}, \omega_{c}\right.$ and $\left.R\right)$ and WLF coefficients $\left(C_{1}, C_{2}\right)$ calculated from regression analyses.

In general terms, it was observed that in both considered ageing states, polymer modification produced a reduction in $C_{1}$ and $C_{2}$. Such an outcome is consistent with findings reported in studies that indicate that the use of SBR and PBR can cause a significant change of the temperature dependency of base bitumen $[9,15,18]$.

As expected, the addition of both polymers caused a hardening effect that was reflected by the progressive reduction of crossover frequency as a function of polymer dosage. In such a context, PBR polymers proved to be more effective, leading to lower values of $\omega_{c}$ in comparison to those obtained for SBR-modified binders. In the case of PBR polymers, the abovementioned hardening was greater for the premium quality product, whereas such an effect was recorded for the SBR modifiers only for tests carried out on unaged samples.

Both SBR and PBR polymers induced a remarkable increase in the rheological parameter R, thus indicating that the corresponding master curves were flattened out with a more gradual transition from the purely viscous to the glassy state. The effects caused by the two polymers were comparable. In the case of the SBR-modified binders, only slight differences were observed between polymers of different quality. Greater differences were recorded for PBR modified binders, with greater $R$ values associated with the use of the waste product. 
The glassy modulus $G_{g}$, extrapolated from the available data, in most cases, was found to decrease with polymer modification for unaged binders, whereas it increased for RTFO-aged samples. However, these findings would need to be validated by further low temperature tests.

Table 5. Master curve parameters.

\begin{tabular}{cccccccc}
\hline Ageing State & Binder Code & TR & $\begin{array}{c}\boldsymbol{C}_{\mathbf{1}} \\
{[-]}\end{array}$ & $\begin{array}{c}\boldsymbol{C}_{\mathbf{2}} \\
{\left[{ }^{\circ} \mathbf{C}\right]}\end{array}$ & $\begin{array}{c}\boldsymbol{G}_{\boldsymbol{g}} \\
{[\mathbf{P a}]}\end{array}$ & $\begin{array}{c}\boldsymbol{\omega}_{\boldsymbol{c}} \\
{[\mathbf{r a d} / \mathbf{s}]}\end{array}$ & $\begin{array}{c}\boldsymbol{R} \\
{[\mathbf{k P a}]}\end{array}$ \\
\hline Virgin & NB & 20 & 14.05 & 120.31 & $4.98 \times 10^{8}$ & 380.19 & 1.19 \\
RTFO & NB & 20 & 14.29 & 116.03 & $3.38 \times 10^{8}$ & 93.33 & 1.23 \\
\hline \multirow{5}{*}{ Virgin } & SW3 & 20 & 11.67 & 95.41 & $4.52 \times 10^{8}$ & 279.12 & 1.31 \\
& SQ3 & 20 & 12.04 & 98.41 & $4.51 \times 10^{8}$ & 240.43 & 1.34 \\
& SW4 & 20 & 11.69 & 93.97 & $5.21 \times 10^{8}$ & 193.54 & 1.47 \\
& SQ4 & 20 & 12.00 & 96.62 & $4.64 \times 10^{8}$ & 159.04 & 1.48 \\
& SW5 & 20 & 11.70 & 91.67 & $4.65 \times 10^{8}$ & 104.09 & 1.55 \\
\hline \multirow{5}{*}{ RTFO } & SW3 & 20 & 13.37 & 108.76 & $4.35 \times 10^{8}$ & 78.79 & 1.46 \\
& SQ3 & 20 & 13.07 & 101.06 & $4.87 \times 10^{8}$ & 73.46 & 1.47 \\
& SW4 & 20 & 12.63 & 95.64 & $5.08 \times 10^{8}$ & 56.04 & 1.57 \\
& SQ4 & 20 & 12.68 & 98.74 & $5.34 \times 10^{8}$ & 73.10 & 1.54 \\
& SW5 & 20 & 13.18 & 105.99 & $4.68 \times 10^{8}$ & 45.50 & 1.66 \\
\hline \multirow{5}{*}{ Virgin } & PW3 & 20 & 11.74 & 97.54 & $3.93 \times 10^{8}$ & 232.69 & 1.35 \\
& PQ3 & 20 & 11.84 & 96.42 & $3.88 \times 10^{8}$ & 219.05 & 1.30 \\
& PW4 & 20 & 11.29 & 88.67 & $4.94 \times 10^{8}$ & 162.26 & 1.48 \\
& PQ4 & 20 & 12.60 & 101.31 & $4.02 \times 10^{8}$ & 93.56 & 1.41 \\
& PW5 & 20 & 10.78 & 83.23 & $5.16 \times 10^{8}$ & 130.90 & 1.63 \\
\hline \multirow{6}{*}{ RTFO } & PW3 & 20 & 14.05 & 110.00 & $4.42 \times 10^{8}$ & 50.53 & 1.48 \\
& PQ3 & 20 & 13.21 & 103.00 & $3.96 \times 10^{8}$ & 62.73 & 1.39 \\
& PW4 & 20 & 13.67 & 107.28 & $4.11 \times 10^{8}$ & 37.06 & 1.56 \\
& PQ4 & 20 & 12.54 & 96.46 & $4.07 \times 10^{8}$ & 52.15 & 1.51 \\
& PW5 & 20 & 12.67 & 98.37 & $3.69 \times 10^{8}$ & 31.74 & 1.64 \\
\hline \multirow{6}{*}{} & & & & & &
\end{tabular}

In order to assess the specific effects of ageing, reference was made to the $A I$ index defined according to the following expression [40]:

$$
A I=\frac{\left(\omega_{c}\right)_{A}}{\left(\omega_{c}\right)_{U}}
$$

where $\left(\omega_{\mathcal{c}}\right)_{A}$ and $\left(\omega_{c}\right)_{U}$ are the crossover frequencies determined in aged and unaged conditions, respectively.

Calculated values of $A I$ are shown in Figure 8. It can be observed that the binders modified with SBR, w-SBR, and PBR exhibited an ageing level which was lower than that of base bitumen. This is proven by the higher values of $A I$, that progressively increased with polymer dosage. Such an outcome is consistent with the findings of previous investigations, in which it was observed that SBR modification can reduce the rate of oxidation [6,12]. On the contrary, use of the w-PBR polymer led to a reduction in the considered index, thus indicating that it was less effective in reducing the ageing which occurred during RTFO treatment. 


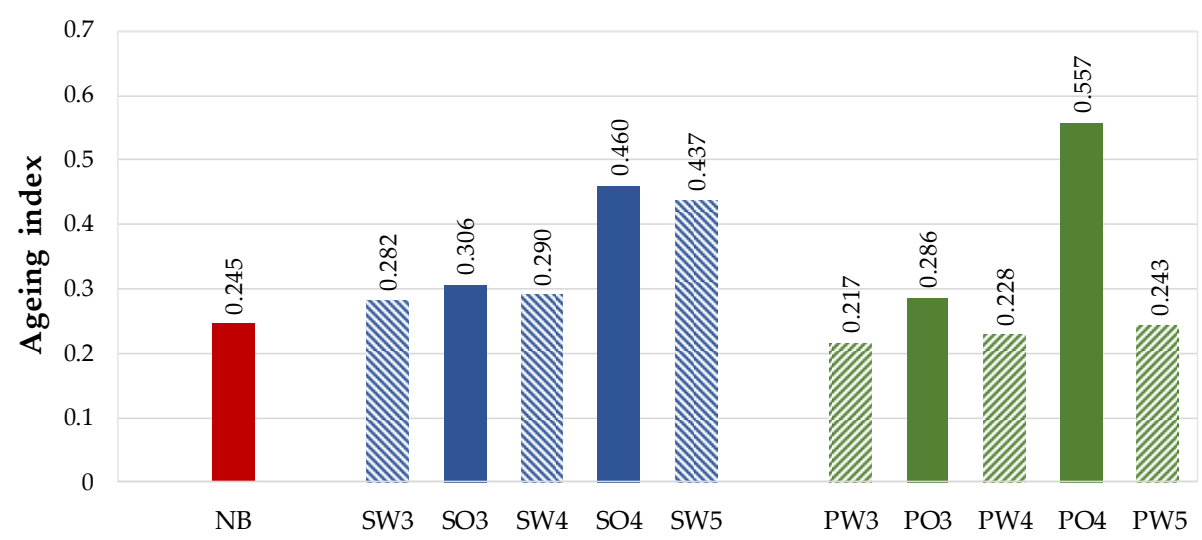

Figure 8. Ageing indexes.

\subsubsection{MSCR Tests}

Results obtained from MSCR tests carried out with a stress of $3.2 \mathrm{kPa}$ are plotted in Figures 9 and 10, which show the values of percent recovery $\left(R_{3.2}\right)$ and non-recoverable creep compliance $\left(\mathrm{J}_{\mathrm{nr} 3.2}\right)$, respectively, as a function of temperature. Represented data refer to binders considered in RTFO-aged conditions.
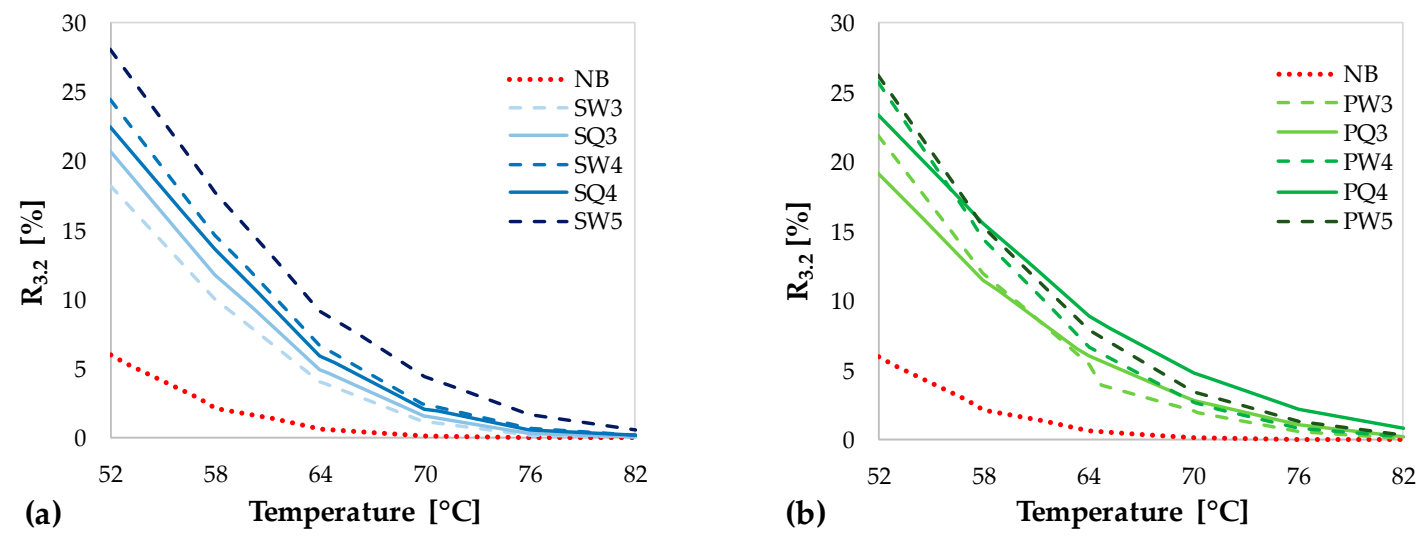

Figure 9. Results of Multiple Stress Creep Recovery (MSCR) tests-percent recovery at $3.2 \mathrm{kPa}$ (RTFO-aged binders): (a) SBR-modified binders; (b) PBR-modified binders.

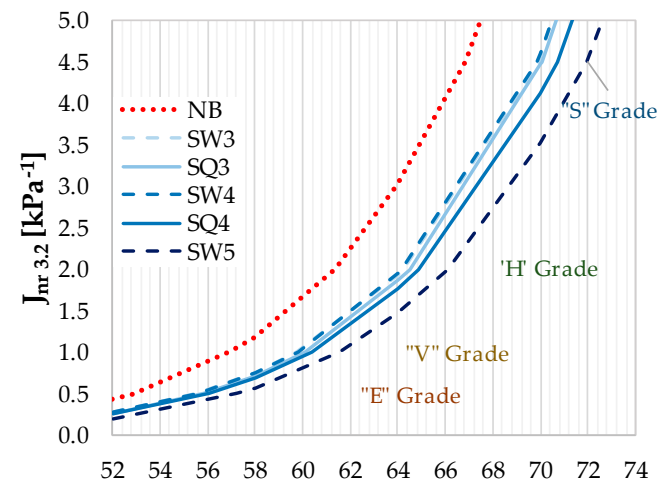

(a)

Temperature $\left[{ }^{\circ} \mathrm{C}\right]$

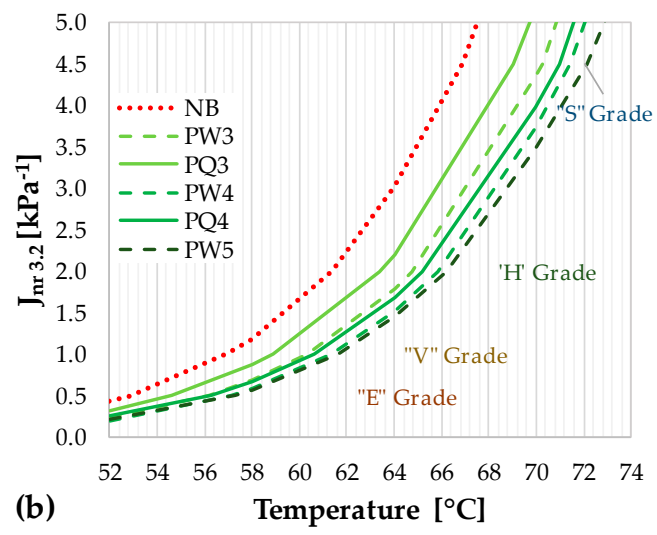

Figure 10. Results of MSCR tests-non-recoverable creep compliance at $3.2 \mathrm{kPa}$ (RTFO-aged binders): (a) SBR-modified binders; (b) PBR-modified binders.

As expected, polymer modification enhanced the elastic response of the base bitumen with a remarkable increase in $R_{3.2}$ and with a significant reduction in $J_{n r 3.2}$. These effects increased with 
polymer dosage and were also found to be dependent upon polymer type and quality. When considering the $R_{3.2}$ plots, no specific ranking could be identified with respect to these last two factors. However, analysis of the $\mathrm{J}_{\mathrm{nr} 3.2}$ data suggests that, in the case of the SBR polymers, the premium quality and waste products were almost equivalent, while a non-negligible difference occurred when comparing the two PBR products. In particular, the w-PBR polymer proved to be more effective than the corresponding premium quality product, with lower values of permanent strain occurring under repeated loading.

Obtained results were consistent with the findings of other researchers, who reported a significant enhancement of the high-temperature characteristics of SBR-modified binders [9,12]. Nevertheless, it should be mentioned that such effects can be strongly dependent upon the specific characteristics of employed polymers and productions technologies, since other investigators found only marginal improvements in similar conditions $[8,10,11]$.

A synthetic assessment of MSCR test results was carried out by referring to the grading criteria described in AASHTO M332-14, which identify limiting values of $\mathrm{J}_{\mathrm{nr} 3.2}$ for different traffic levels. These values are fixed at $4.5 \mathrm{kPa}^{-1}, 2.0 \mathrm{kPa}^{-1}, 1.0 \mathrm{kPa}^{-1}$, and $0.5 \mathrm{kPa}^{-1}$ for traffic levels indicated as "S" (standard), " $\mathrm{H}$ " (heavy), "V" (very heavy), and " $\mathrm{E}$ " (extremely heavy), respectively. Thus, temperatures at which these values are reached, referred to as high critical temperatures $\left(T_{c}\right)$, were calculated for all binders. Corresponding results are listed in Table 6 . For comparative purposes, Table 6 also contains the values of test temperatures at which the $G^{*} / \sin \delta$ parameter was found to be equal to $1.0 \mathrm{kPa}$ for samples tested in their unaged state (as per AASHTO M332-14). Such an assessment was based on the results of the SAOS tests discussed in Section 3.3.1.

Table 6. High critical temperatures.

\begin{tabular}{|c|c|c|c|c|c|}
\hline \multirow[t]{2}{*}{ Binder Code } & \multirow{2}{*}{$\begin{array}{c}\text { High } \mathrm{T}_{\mathrm{c}} \text { from } \\
G^{*} / \sin \delta \text { Criterion } \\
\text { (Unaged Samples) }\left[{ }^{\circ} \mathrm{C}\right]\end{array}$} & \multicolumn{4}{|c|}{$\begin{array}{c}\text { High } \mathrm{T}_{\mathrm{c}} \text { from } \\
\text { MSCR Criteria } \\
\text { (RTFO-Aged Samples) }\left[{ }^{\circ} \mathrm{C}\right]\end{array}$} \\
\hline & & "S" & “H” & “V” & "E" \\
\hline NB & 68.9 & 66.8 & 61.4 & 56.9 & 52.9 \\
\hline SW3 & 71.9 & 69.9 & 64.2 & 59.8 & 55.5 \\
\hline SQ3 & 72.2 & 70.0 & 64.5 & 60.1 & 55.8 \\
\hline SW4 & 74.4 & 69.9 & 64.2 & 59.8 & 55.6 \\
\hline SQ4 & 74.3 & 70.7 & 64.9 & 60.4 & 56.0 \\
\hline SW5 & 76.6 & 71.9 & 66.1 & 61.5 & 57.2 \\
\hline PW3 & 72.7 & 70.3 & 64.7 & 60.3 & 56.2 \\
\hline PQ3 & 72.1 & 69.0 & 63.4 & 58.9 & 54.6 \\
\hline PW4 & 75.2 & 71.4 & 65.9 & 61.4 & 57.2 \\
\hline PQ4 & 76.3 & 70.9 & 65.2 & 60.7 & 56.3 \\
\hline PW5 & 77.1 & 72.2 & 66.2 & 61.6 & 57.3 \\
\hline
\end{tabular}

Evaluation of the temperature values reported in Table 6 confirmed the comments made when discussing the plots presented in Figures 9 and 10. The two types of polymer yielded similar variations of the high critical temperatures, which were found to be between $1.7^{\circ} \mathrm{C}$ and $5.4^{\circ} \mathrm{C}$. Greater changes were recorded when considering the $\mathrm{T}_{\mathrm{C}}$ values associated to the threshold value of $G^{*} / \sin \delta$.

\subsubsection{LAS Tests}

As mentioned in Section 2.4, results coming from LAS tests were processed by referring to the failure criterion proposed by Wang et al., based on the evaluation of the maximum value of the stored pseudo-strain energy density (PSE) [33,34]. An example of this type of analysis is provided in Figure 11, where such an identification of failure conditions is compared to that which derives from the maximum shear stress criterion indicated in AASHTO TP101-14. In most cases, strain at failure coming from the energy-based criterion was found to be higher than the one associated to maximum stress. 

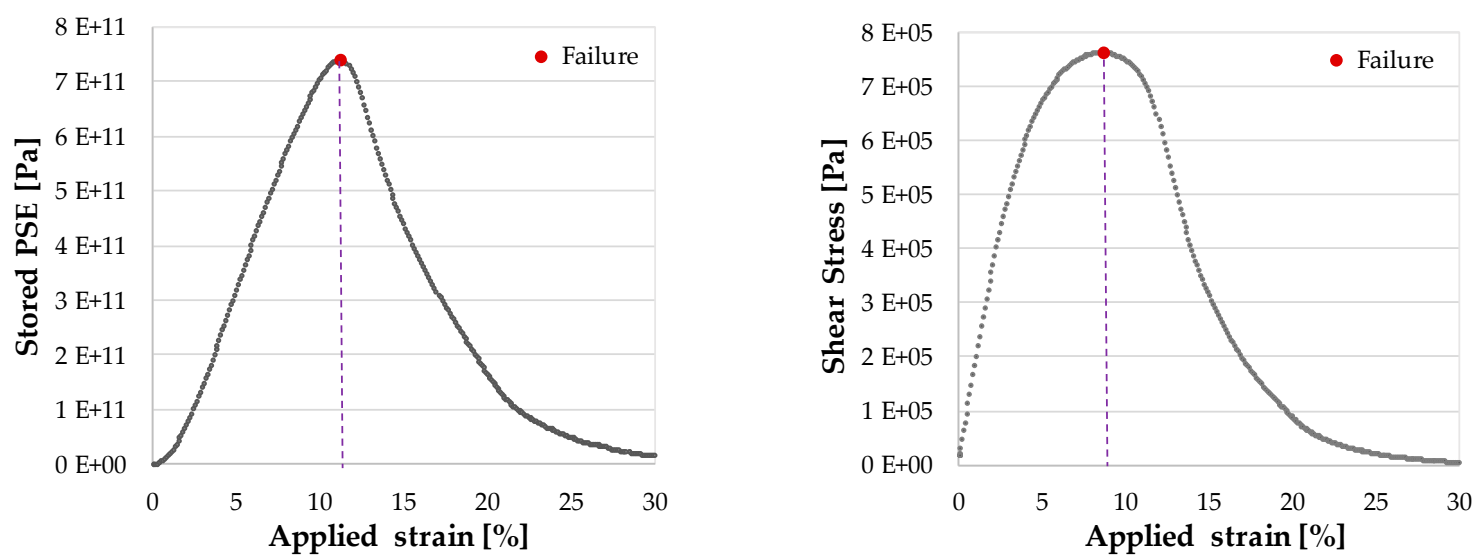

Figure 11. Results of Linear Amplitude Sweep (LAS) tests—identification of failure conditions: (a) at maximum stored pseudo-strain energy density; (b) at maximum shear stress.

Fatigue lines derived from the processing of experimental data are shown in Figure 12, where they are separately represented for SBR-modified and PBR-modified binders. The fatigue line and fitting parameters of neat bitumen are also displayed for comparative purposes. Values of fitting parameters $\mathrm{A}$ and $\mathrm{B}$, as per Equation (5), are listed in Table 7 for all binders subjected to testing.
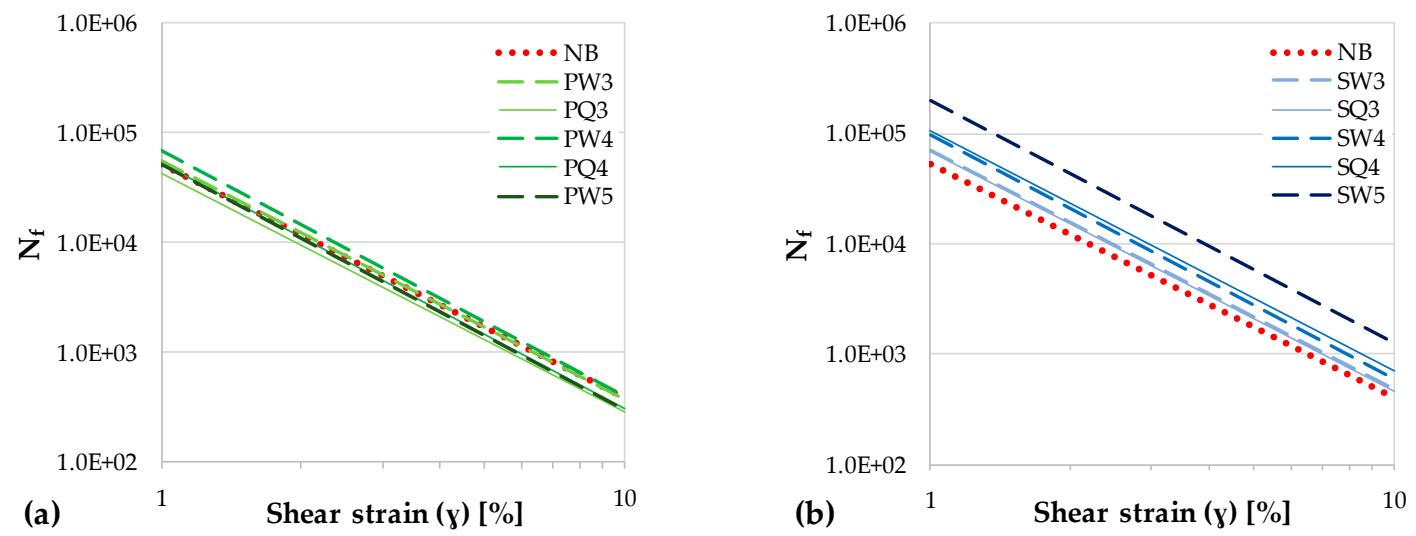

Figure 12. Results of LAS tests-fatigue lines: (a) SBR-modified binders; (b) PBR-modified binders.

Table 7. Fitting parameters of fatigue lines.

\begin{tabular}{ccccccccccccc}
\hline Parameter & NB & SW3 & SQ3 & SW4 & SQ4 & SW5 & PW3 & PQ3 & PW4 & PQ4 & PW5 \\
\hline A & $5.3 \times 10^{4}$ & $6.9 \times 10^{4}$ & $6.8 \times 10^{4}$ & $9.7 \times 10^{4}$ & $1.1 \times 10^{5}$ & $2.0 \times 10^{5}$ & $5.7 \times 10^{4}$ & $4.4 \times 10^{4}$ & $6.8 \times 10^{4}$ & $5.3 \times 10^{4}$ & $5.2 \times 10^{4}$ \\
B & 2.122 & 2.157 & 2.162 & 2.217 & 2.180 & 2.193 & 2.175 & 2.182 & 2.224 & 2.238 & 2.229 \\
\hline
\end{tabular}

From the analysis of Figure 12, it can be observed that use of the two types of polymer (SBR and PBR) yielded completely different effects in terms of damage under repeated loading. The SBR products clearly induced an improvement in fatigue resistance, with curves that were progressively shifted upwards as a function of polymer dosage. Furthermore, similar effects were obtained with the premium quality and waste products, which led to almost overlapping fatigue curves. On the contrary, the PBR polymers (both of premium quality and of the waste type) did not have any appreciable effect on the fatigue response of the base bitumen. All fatigue lines were contained within a very narrow range, with no possibility of discriminating between binders containing PBR polymers with different dosage or quality. Such an outcome seems to be consistent with the results of FTIR analyses (see Section 3.1), which indicated that the PBR polymers were dissolved in the bitumen phase.

The outcomes synthesized above were confirmed by analyzing the values of the A and B parameters presented in Table 7. SBR modification produced a clear increase in the A parameter and had a marginal 
effect on strain sensitivity, with only a small increase of parameter B. On the contrary, PBR polymers had a minor effect on the A parameter, while they produced an increase of parameter $B$, which was slightly higher than that induced by SBR modification.

\section{Conclusions}

Based on the results presented in this paper, conclusions can be drawn with respect to the possible use of waste products, coming from the production of styrene butadiene rubber (SBR) and polybutadiene rubber (PBR), as bitumen modifiers.

The outcomes of the advanced performance-related rheological tests indicate that the waste SBR product considered in the investigation is equivalent to the corresponding premium quality polymer. In particular, in the range of dosages that were considered in the study ( $3-5 \%$ by weight of neat bitumen), such a product led to the preparation of PMBs characterized by a highly elastic response in a wide range of temperatures and loading frequencies, and by a satisfactory behavior in terms of their resistance to permanent deformation, fatigue damage, and ageing.

Different results were obtained when considering the PBR polymers. Although it was found that such products enhanced the elasticity and stiffness of neat bitumen, it was also observed that they had a limited effect on the control of ageing and that they produced no benefits in terms of fatigue resistance. Overall, no significant differences were highlighted when comparing the waste polymer to the corresponding premium quality product.

Results of rheological analyses were consistent with those coming from chemical characterization tests. In particular, it was observed that the two types of polymer exhibited totally different interactions with neat bitumen. In the case of the SBR polymers, obtained results suggest the formation of dispersed elastic domains, whereas a high level of dissolution was hypothesized for the PBR polymers.

Further investigations are needed in order to validate the findings synthesized above. Assessment of the full potential of both types of polymer will require consideration of component materials coming from different sources, evaluation of plant-produced PMBs, and analysis of performance-related properties of corresponding bituminous mixtures. Furthermore, the rheological and failure behavior at low service temperatures deserve to be addressed by means of specific tests.

Author Contributions: Conceptualization, S.Y. and M.A.; methodology, M.A., D.D. and E.S.; investigation, S.Y.; resources, M.A. and E.S.; data analysis, S.Y. and D.D.; writing-original draft preparation, S.Y.; writing一review and editing, D.D. and E.S. All authors have read and agreed to the published version of the manuscript.

Funding: This research received no external funding.

Conflicts of Interest: The authors declare no conflict of interest.

\section{References}

1. Porto, M.; Caputo, P.; Loise, V.; Eskandarsefat, S.; Teltayev, B.; Rossi, C.O. Bitumen and Bitumen Modification: A Review on Latest Advances. App. Sci. 2019, 9, 742. [CrossRef]

2. Becker, Y.; Mendez, M.P.; Rodríguez, Y. Polymer modified asphalt. Vis. Tecnol. 2001, 9, 39-50.

3. Zhu, J.; Birgisson, B.; Kringos, N. Polymer modification of bitumen: Advances and challenges. Eur. Polym. J. 2014, 54, 18-38. [CrossRef]

4. Yildirim, Y. Polymer modified asphalt binders. Constr. Build. Mater. 2007, 21, 66-72. [CrossRef]

5. Behnood, A.; Modiri Gharehveran, M. Morphology, rheology, and physical properties of polymer-modified asphalt binders. Eur. Polym. J. 2019, 112, 766-791. [CrossRef]

6. McNally, T. (Ed.) Polymer Modified Bitumen: Properties and Characterisation; Woodhead Publishing Ltd.: Cambridge, UK, 2011.

7. Vamegh, M.; Ameri, M. Rutting performance of road pavement asphalt binders modified by polymers. Proc. Inst. Civ. Eng. 2019, 1-8. [CrossRef]

8. Zhang, B.; Xi, M.; Zhang, D.; Zhang, H.; Zhang, B. The effect of styrene-butadiene-rubber/montmorillonite modification on the characteristics and properties of asphalt. Constr. Build. Mater. 2009, 23, 3112-3117. [CrossRef] 
9. Lee, Y.J.; France, L.M.; Hawley, M.C. The effect of network formation on the rheological properties of SBR modified asphalt binders. Rubber Chem. Technol. 1997, 70, 256-263. [CrossRef]

10. Zhang, F.; Hu, C. Influence of aging on thermal behavior and characterization of SBR compound-modified asphalt. J. Therm. Anal. Calorim. 2014, 115, 1211-1218. [CrossRef]

11. Liang, P.; Liang, M.; Fan, W.; Zhang, Y.; Qian, C.; Ren, S. Improving thermo-rheological behavior and compatibility of SBR modified asphalt by addition of polyphosphoric acid (PPA). Constr. Build. Mater. 2017, 139, 183-192. [CrossRef]

12. Zhao, D.; Lei, M.; Yao, Z. Evaluation of polymer-modified hot-mix asphalt: Laboratory characterization. J. Mater. Civ. Eng. 2009, 21, 163-170. [CrossRef]

13. Tsantilis, L.; Dalmazzo, D.; Baglieri, O.; Santagata, E. Effect of SBS molecular structure on the rheological properties of ternary nanomodified bituminous binders. Constr. Build. Mater. 2019, 222, 183-192. [CrossRef]

14. Zhang, F.; Yu, J. The research for high-performance SBR compound modified asphalt. Constr. Build. Mater. 2010, 24, 410-418. [CrossRef]

15. Zhang, J.; Wang, J.; Wu, Y.; Sun, W.; Wang, Y. Thermal behaviour and improved properties of SBR and SBR/natural bitumen modified bitumens. Iran. Polym. J. 2009, 18, 465-478.

16. Ameri, M.; Yeganeh, S.; Valipour, P.E. Experimental evaluation of fatigue resistance of asphalt mixtures containing waste elastomeric polymers. Constr. Build. Mater. 2019, 198, 638-649. [CrossRef]

17. Yousefi, A.A. Rubber-modified bitumens. Iran. Polym. J. 2002, 11, 303-309.

18. Daryaee, D.; Ameri, M.; Mansourkhaki, A. Utilizing of waste polymer modified bitumen in combination with rejuvenator in high reclaimed asphalt pavement mixtures. Constr. Build. Mater. 2020, 235, 117516. [CrossRef]

19. Yousefi, A.A. Polymer-modified bitumen from the wastes of petrochemical plants. Iran. Polym. J. 2009, 18, 207-215.

20. Polacco, G.; Filippi, S.; Merusi, F.; Stastna, G. A review of the fundamentals of polymer-modified asphalts: Asphalt/polymer interactions and principles of compatibility. Adv. Colloid Interfac. 2015, 224, 72-112. [CrossRef]

21. Nivitha, M.R.; Prasad, E.; Krishnan, J.M. Ageing in modified bitumen using FTIR spectroscopy. Int. J. Pavement Eng. 2016, 17, 565-577. [CrossRef]

22. Lesueur, D. The colloidal structure of bitumen: Consequences on the rheology and on the mechanisms of bitumen modification. Adv. Colloid Interfac. 2009, 145, 42-82. [CrossRef] [PubMed]

23. Leroy, G. Bitumen analysis by thin layer chromatography (Iatroscan). In Proceedings of the 4th Eurobitume Congress, Madrid, Spain, 4-6 October 1989; pp. 166-170.

24. Ecker, A. The application of iatroscan-technique for analysis of bitumen. Petrol. Coal 2001, 1, 51-53.

25. Santagata, E.; Baglieri, O.; Dalmazzo, D.; Tsantilis, L. Rheological and chemical investigation on the damage and healing properties of bituminous binders. J. Assoc. Asphalt Pav. 2009, 28, 567.

26. Weigel, S.; Stephan, D. Differentiation of bitumen according to the refinery and ageing state based on FTIR spectroscopy and multivariate analysis methods. Mater. Struct. 2018, 51, 130. [CrossRef]

27. Christensen, D.W.; Anderson, D.A. Interpretation of dynamic mechanical test data for paving grade asphalt cements (with discussion). J. Assoc. Asphalt Pav. 1992, 61, 67-116.

28. Ferry John, D. Viscoelastic Properties of Polymers, 3rd ed.; John Wiley \& Sons: New York, NY, USA, 1980.

29. D'Angelo, J.; Dongré, R. Superpave binder specifications and their performance relationship to modified binders. In Proceedings of the Forty-Seventh Annual Conference of the Canadian Technical Asphalt Association (CTAA), Calgary, Alberta, 2002; pp. 91-103.

30. Santagata, E.; Baglieri, O.; Dalmazzo, D.; Tsantilis, L. Evaluation of the anti-rutting potential of polymer-modified binders by means of creep-recovery shear tests. Mater. Struct. 2013, 46, 1673-1682. [CrossRef]

31. D'Angelo, J.A. The relationship of the MSCR test to rutting. Road Mater. Pavement 2009, 10 (Suppl. 1), 61-80. [CrossRef]

32. Hintz, C.; Bahia, H. Simplification of linear amplitude sweep test and specification parameter. Transport. Res. Rec. 2013, 2370, 10-16. [CrossRef]

33. Safaei, F.; Castorena, C.; Kim, Y.R. Linking asphalt binder fatigue to asphalt mixture fatigue performance using viscoelastic continuum damage modeling. Mech. Time-Depend. Mat. 2016, 20, 299-323. [CrossRef]

34. Wang, C.; Xie, W.; Chen, Y.; Diab, A.; You, Z. Refining the Calculation Method for Fatigue Failure Criterion of Asphalt Binder from Linear Amplitude Sweep Test. J. Mater. Civ. Eng. 2017, 30, 04017286. [CrossRef] 
35. Shen, S.; Chiu, H.M.; Huang, H. Characterization of fatigue and healing in asphalt binders. J. Mater. Civ. Eng. 2010, 22, 846-852. [CrossRef]

36. Santagata, E.; Baglieri, O.; Tsantilis, L.; Chiappinelli, G. Fatigue and healing properties of nano-reinforced bituminous binders. Int. J. Fatigue 2015, 80, 30-39. [CrossRef]

37. Masson, J.F.; Pelletier, L.; Collins, P. Rapid FTIR method for quantification of styrene-butadiene type copolymers in bitumen. J. Appl. Polym. Sci. 2001, 79, 1034-1041. [CrossRef]

38. Fawcett, A.H.; McNally, T.M. A dynamic mechanical and thermal study of various rubber-bitumen blends. J. Appl. Polym. Sci. 2000, 77, 586-601. [CrossRef]

39. Airey, G.D. Use of black diagrams to identify inconsistencies in rheological data. Road Mater. Pavement 2002, 3, 403-424. [CrossRef]

40. Santagata, E.; Baglieri, O.; Tsantilis, L.; Dalmazzo, D. Rheological characterization of bituminous binders modified with carbon nanotubes. Procedia Soc. Behav. 2012, 53, 546-555. [CrossRef]

(C) 2020 by the authors. Licensee MDPI, Basel, Switzerland. This article is an open access article distributed under the terms and conditions of the Creative Commons Attribution (CC BY) license (http://creativecommons.org/licenses/by/4.0/). 